See discussions, stats, and author profiles for this publication at: https://www.researchgate.net/publication/279458095

\title{
Parent, Alkylated, and Sulfur/Oxygen-Containing Polycyclic Aromatic Hydrocarbons in Mainstream Smoke from 13 Brands of Chinese Cigarettes
}

ARTICLE in ENVIRONMENTAL SCIENCE \& TECHNOLOGY · JUNE 2015

Impact Factor: $5.33 \cdot$ DOI: 10.1021/acs.est.5b01108 · Source: PubMed

CITATIONS

2

8 AUTHORS, INCLUDING:

Xinming Wang

Chinese Academy of Sciences

181 PUBLICATIONS $\quad 3,860$ CITATIONS

SEE PROFILE

\section{Xiang Ding}

Chinese Academy of Sciences

43 PUBLICATIONS 714 CITATIONS

SEE PROFILE
READS

142
Jianhui Tang

Chinese Academy of Sciences

62 PUBLICATIONS 1,018 CITATIONS

SEE PROFILE

Gan Zhang

Chinese Academy of Sciences

346 PUBLICATIONS 8,863 CITATIONS

SEE PROFILE 


\title{
Parent, Alkylated, and Sulfur/Oxygen-Containing Polycyclic Aromatic Hydrocarbons in Mainstream Smoke from 13 Brands of Chinese Cigarettes
}

 \\ and Gan Zhang ${ }^{\dagger}$
}

${ }^{\dagger}$ State Key Laboratory of Organic Geochemistry, Guangzhou Institute of Geochemistry, Chinese Academy of Sciences, Guangzhou 510640, China

${ }^{\ddagger}$ South China Institute of Environmental Sciences, Ministry of Environmental Protection, Guangzhou 510655, China

${ }^{\S}$ Guangdong Key Laboratory of Environmental Protection and Resources Utilization, Guangzhou Institute of Geochemistry, Chinese Academy of Sciences, Guangzhou 510640, China

"Shandong Provincial Key Laboratory of Coastal Environmental Processes, Yantai Institute of Coastal Zone Research, Chinese Academy of Sciences, Yantai, Shandong 264003, China

\section{Supporting Information}

\begin{abstract}
China has the world's largest population of smokers with serious health consequences, yet we know a very limited spectrum of hazardous chemicals in cigarette smoke even for carcinogenic polycyclic aromatic hydrocarbons (PAHs). Here, we chose 13 popular cigarette brands sold in China markets, collected particulate matters in mainstream smoke using filter pads and an automatic smoking machine, and analyzed 56 PAHs, including 31 parent, 18 alkylated, and 7 sulfur/oxygen-containing PAHs (S/O PAHs). The 56 PAHs in mainstream smoke totaled from $244.2 \pm 28.5$ to $10254.8 \pm 481.5 \mathrm{ng} \mathrm{cig}^{-1}$; parent, alkylated, and S/O PAHs shared 16-23\%, 64-74\%, and 6-18\%, respectively. Benzo[a]pyrene (BaP) ranged 1.1-41.6 ng cig ${ }^{-1}$, while $\mathrm{BaP}$ equivalent concentrations $\left(\mathrm{BaP}_{\text {eq }}\right)$ ranged 3.6$120.2 \mathrm{ng} \mathrm{cig}^{-1}$, but contributions to $\mathrm{BaP}_{\text {eq }}$ by individual carcinogenic $\mathrm{PAH}$ species varied with cigarette brands. When these cigarette smoke source profiles were pooled together with those of other combustion ones available in the literature, we

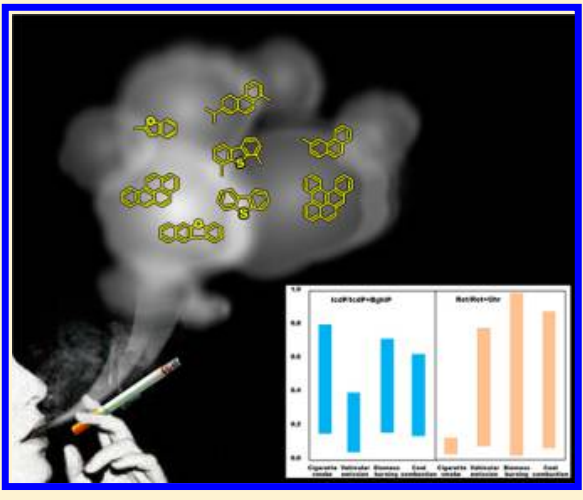
found that widely used diagnostic ratios of parent PAHs failed to distinguish cigarette smoke from other combustion sources, except that the ratio indeno[1,2,3-cd]pyrene/(indeno[ $1,2,3-\mathrm{cd}]$ pyrene + benzo[g,h,i]perylene) can largely separate cigarette smoke from vehicular emissions and that the ratio of Retene/(Retene + chrysene) can further discriminate cigarette smoke from coal combustion when alkylated PAHs are involved.
\end{abstract}

\section{INTRODUCTION}

Polycyclic aromatic hydrocarbons (PAHs) are known to cause cancer in humans. They are ubiquitous in ambient air largely from incomplete combustion of fossil fuels and/or biomass burning, yet environmental tobacco smoke (ETS), either mainstream or side-stream, contributes substantially to PAHs in indoor microenvironments, ${ }^{1,2}$ particularly in smoker's homes. ${ }^{3}$ As PAHs are among the most potent carcinogens in cigarette smoke and tobacco smoke-derived PAHs bear a large burden in human exposure to this class of carcinogens, ${ }^{4}$ characterizing compositions and levels of PAHs in cigarette smoke is of wide and enduring concern for the protection of public health.

Mainstream smoke (MS), referring specifically to the smoke that a smoker inhales and then exhales, represents the direct health hazard to smokers though voluntary inhalation. Previous studies have revealed the presence of PAHs and other pollutants in $\mathrm{MS},^{1,5-7}$ and among them, benzo[a]pyrene
(BaP) was the most studied species due to its ability to induce lung tumors. ${ }^{8}$ Besides $\mathrm{BaP}$, some other PAHs within the USEPA's 16 priority PAHs are also identified as probably or possibly carcinogenic to humans by agencies like the International Agency for Research on Cancer (IARC). ${ }^{1}$ Consequently, the 16 priority PAHs or their subsets in ETS were investigated concerning their levels, compositions, ${ }^{1,6,9}$ and toxicity, ${ }^{5}$ as well as the influence of smoking conditions and cigarette design on the chemical delivery. ${ }^{7,10,11}$ However, as cigarette smoke is a complex mixture with multiple classes of chemical compounds, more PAHs, such as alkylated and sulfur/oxygen (S/O) PAHs, also exist in cigarette smoke, ${ }^{12,13}$ either being possible human carcinogens or promoters for the carcinogenicity of other

Received: March 4, 2015

Revised: May 28, 2015

Accepted: June 29, 2015

Published: June 29, 2015 
PAHs. ${ }^{6}$ Previous studies have evidenced that some alkylated and S/O PAHs were more toxic than their parent ones. ${ }^{14,15}$ Hence, accurate evaluation of the toxicity of cigarette smoke requires more $\mathrm{PAH}$ species to be measured. Unfortunately, there is little quantitative data about these additional PAHs. Only a few studies reported the concentrations of methylnaphthalenes, ${ }^{7}$ methylphenanthrenes/methylanthracenes and methylpyrenes, $^{12}$ and 5-methylchrysene ${ }^{16}$ in the MS particulates.

China is the world's leading tobacco producer and has a third of the world's tobacco consumers. ${ }^{4}$ However, most of the published researches focused on PAHs in reference cigarettes and/or commercial cigarette brands outside of China. Only a few studies are available for cigarettes smoke PAHs in China, ${ }^{4,17,18}$ and the target compounds were still limited within the 16 priority PAHs. To our best knowledge, only one study published in English reported 9 priority PAHs and other harmful chemicals in 20 brands of Chinese cigarettes. ${ }^{4}$ In this study, we measured the levels of $56 \mathrm{PAHs}$, including 31 parent, 18 alkylated, and 7 S/O PAHs in the MS particulates from 13 popular Chinese cigarette brands so as to complement these deficiencies. PAH levels in reference cigarettes were also measured for comparison with previous studies. The $\mathrm{BaP}$ equivalent $\left(\mathrm{BaP}_{\mathrm{eq}}\right)$ concentrations were further calculated to indicate carcinogenic potency of PAHs using our current data. As diagnostic ratios have been widely used to identify $\mathrm{PAH}$ sources $^{19,20}$ and utilizing the alkylated and S/O analogues may facilitate source discrimination, ${ }^{21,22}$ here, we finally evaluate whether PAH (including parent, alkylated, and S/O PAHs) ratios can distinguish cigarette smoke from other sources, using published source profiles for combustion sources together with our data.

\section{EXPERIMENTAL SECTION}

Materials. Sixteen priority PAHs and deuterated PAHs (naphthalene-d8, acenaphthene-d10, phenanthrene-d10, chrysene-d12, perylene-d12) were obtained from Ultra Scientific, Inc. (North Kingstow, RI, U.S.A.). A standard mixture solution of 10 PAHs (1-methylnaphthalene, 2-methylnaphthalene, biphenyl, 2,6-dimethylnaphthalene, 2,3,6-trimethylnaphthalene, 2-methylphenanthrene, 1-methylphenanthrene, 3,6-dimethylphenanthrene, benzo[e]pyrene and perylene) was obtained from AccuStandards, Inc. (New Haven, CT, U.S.A.). A standard mixture solution of $8 \mathrm{~S} / \mathrm{O}$ PAHs (dibenzofuran, 1methyldibenzofuran, dibenzothiophene, 4-methyldibenzothiophene, 2-methyldibenzothiophene, 3-methyldibenzothiophene, benzonaphtho $[2,1-d]$ thiophene, benzonaphtho[2,3-d]thiophene) was purchased from Chiron AS (Trondheim, ST, Norway). Hexamethylbenzene and coronene were purchased from Aldrich Chemical Co. (Milwaukee, WI, U.S.A.). Reference cigarettes, $1 \mathrm{R} 3 \mathrm{~F}$ and $2 \mathrm{R} 4 \mathrm{~F}$, were obtained from the University of Kentucky (Lexington, KY, U.S.A.). Domestic commercial cigarettes were purchased from various retail sources in China. Cambridge filter pads (CFPs) used to collect MS particulate matter were obtained from Whatman (Maidstone, U.K.).

Smoke Collection. Prior to smoking, the cigarettes and CFPs were conditioned at constant relative humidity (60\%) and temperature $\left(22{ }^{\circ} \mathrm{C}\right)$ for no less than $48 \mathrm{~h}$ using a temperature and humidity chamber (WTC binder, Germany). MS total particulate matter (TPM) generated following U.S. Federal Trade Commission (FTC)/International Standard Organization (ISO) conditions (60 s puff interval, $2 \mathrm{~s}$ puff duration, and $35 \mathrm{~mL}$ puff volume) was collected on individual CFPs using a Borgwaldt (Germany) RM200 20-port automatic smoking machine. The cigarettes were smoked to a butt length of $23 \mathrm{~mm}$ or the length of the filter overwrap plus $3 \mathrm{~mm}$, whichever was longer, using the industry-standard Cambridge filter pad holder. Three replicate samples were collected per cigarette type with 20 cigarettes smoked for each sample. Table $S 1$ of the Supporting Information presents the specification and average puff count for each type of cigarette.

Sample Preparation and GC/MS Analysis. The analytical procedure used for extraction, separation, and measurement of PAHs was detailed elsewhere, ${ }^{23,24}$ and only a brief description is given here. Before extraction, each CFP was spiked with the deuterated $\mathrm{PAH}$ standards as surrogates, and then Soxhlet-extracted with dichloromethane for $72 \mathrm{~h}$. The extracts were concentrated to $1 \mathrm{~mL}$, solvent-exchanged to redistilled hexane, and then separated into two fractions using a 1:2 alumina/silica column chromatography. The first fraction containing nonpolar compounds was eluted by $30 \mathrm{~mL}$ of hexane. The second fraction, containing PAHs, was eluted by $70 \mathrm{~mL}$ of dichloromethane/hexane $(3: 7 \mathrm{v} / \mathrm{v})$, concentrated to $\sim 1 \mathrm{~mL}$, and blown to $\sim 200 \mu \mathrm{L}$ under a gentle stream of nitrogen. A total of $8 \mu \mathrm{L}$ of a $50 \mu \mathrm{g} \mathrm{mL}^{-1}$ hexamethylbenzene internal standard was added to the samples before instrumental analysis.

The samples were analyzed using an Agilent GC-MS (6890$5973 \mathrm{~N})$ equipped with a HP-5 capillary column $(50 \mathrm{~m} \times 0.32$ $\mathrm{mm} \times 0.17 \mu \mathrm{m})$. The column temperature was initiated at 80 ${ }^{\circ} \mathrm{C}$ (held for $5 \mathrm{~min}$ ) and increased to $290{ }^{\circ} \mathrm{C}$ at $3{ }^{\circ} \mathrm{C} \mathrm{min}^{-1}$ (held for $30 \mathrm{~min}$ ). An aliquot of $1 \mu \mathrm{L}$ was injected in split mode with a solvent delay of 6 min. Parent, alkylated, and S/O PAHs were identified based on their mass spectra and retention times. For those with authentic standards, quantitation was performed using the internal calibration method with the five-point calibration curves, and for alkylated PAHs without authentic standards, their amounts were approximated with their isomers/homologues or parent PAHs closest in retention times as the alternative standards.

Recoveries were evaluated by the deuterated surrogates spiked to the samples. The mean recoveries were $76 \pm 20 \%, 89$ $\pm 13 \%, 98 \pm 15 \%, 89 \pm 16 \%$, and $82 \pm 16 \%$, respectively, for naphthalene- $\mathrm{d} 8$, acenaphthalene- $\mathrm{d} 8$, phenanthrene-d10, chrysene-d12, and perylene-d12. The relative standard deviations (RSDs) of individual PAHs except for naphthalene were all within $15 \%$ among the three replicate samples collected per cigarette brand.

\section{RESULTS AND DISCUSSION}

PAH Levels in Reference Cigarettes. We measured 56 PAHs in MS for 1R3F and 2R4F Kentucky reference cigarettes using our method (Table S2, Supporting Information). Individual PAHs for 1R3F cigarettes showed levels 1.1-2.5 times that for 2R4F ones, and the total PAH levels in 1R3F $\left(4208.8 \pm 746.7 \mathrm{ng} \mathrm{cig}^{-1}\right)$ were 1.6 times that in $2 \mathrm{R} 4 \mathrm{~F}(2564.3$ $\left.\pm 134.8 \mathrm{ng} \mathrm{cig}{ }^{-1}\right)$. However, TPM normalized PAH levels (PAHs/TPM) for 1R3F (303.9 $\pm 51.6 \mathrm{ng} \mathrm{mg}^{-1}$ ) were just slightly higher than that for $2 \mathrm{R} 4 \mathrm{~F}\left(272.9 \pm 5.3 \mathrm{ng} \mathrm{mg}^{-1}\right)$. Considering $1 \mathrm{R} 3 \mathrm{~F}$ is close to $2 \mathrm{R} 4 \mathrm{~F}$ in tobacco blend, higher $\mathrm{PAH}$ yields for $1 \mathrm{R} 3 \mathrm{~F}$ may be due to its lower filter ventilation than $2 \mathrm{R} 4 \mathrm{~F}$. $2 \mathrm{R} 4 \mathrm{~F}$ is designed as the substitute of $1 \mathrm{R} 4 \mathrm{~F},{ }^{25}$ and both of them are examples of American blended cigarettes with filler consisting of bright, burley, oriental, and reconstituted tobaccos. $^{1}$ Literature data of these two types of reference cigarettes smoked under FTC/ISO conditions are listed in Table 1 for comparison. Among the $\mathrm{PAH}$ levels for $2 \mathrm{R} 4 \mathrm{~F}$ 
Table 1. Measured PAH Levels $\left(\mathrm{ng} \mathrm{cig}^{-1}\right)$ in Reference Cigarettes from Different Studies

\begin{tabular}{|c|c|c|c|c|c|c|c|c|c|c|}
\hline & $1 \mathrm{R} 3 \mathrm{~F}^{a}$ & $2 \mathrm{R}_{4} \mathrm{~F}^{a}$ & $2 \mathrm{R} 4 \mathrm{~F}^{b}$ & $2 \mathrm{R} 4 \mathrm{~F}^{c}$ & $2 \mathrm{R} 4 \mathrm{~F}^{d}$ & $1 \mathrm{R} 4 \mathrm{~F}^{d}$ & $1 \mathrm{R} 4 \mathrm{~F}^{e}$ & $1 \mathrm{R} 4 \mathrm{~F}^{f}$ & $1 \mathrm{R} 4 \mathrm{~F}^{g}$ & $1 \mathrm{R} 4 \mathrm{~F}^{h}$ \\
\hline & GC-MS & GC-MS & LC-MS/MS & GC-MS & GC-MS & GC-MS & GC-MS & GC-MS & GC-MS & GC-MS \\
\hline $\mathrm{Nap}^{i}$ & 90.5 & 36.8 & & & 192 & 350.3 & 236 & & 292.8 & 361.7 \\
\hline Acey & 45.5 & 26.1 & & & 88.3 & 116.9 & 50.4 & & & \\
\hline Ace & 31.4 & 19.7 & & & 51.3 & 84.8 & 25.3 & & & \\
\hline $\mathrm{Fl}$ & 168.9 & 103.8 & & & 156.3 & 217.5 & 119 & & 144.5 & 239 \\
\hline Phe & 126.4 & 90.5 & & & 145.2 & 134.8 & 110 & & 76.3 & 147.7 \\
\hline Ant & 61.7 & 41.8 & & & 69.8 & 74.9 & 38.1 & & 34.5 & 35.8 \\
\hline Flu & 72.5 & 46.6 & & & 63 & 74.4 & 46.2 & & 42.6 & 51.6 \\
\hline Pyr & 53.4 & 38.7 & & 35.3 & 49.5 & 48.6 & 33.2 & & 27.9 & 32.1 \\
\hline $\mathrm{BaA}$ & 22.2 & 18.1 & 33.5 & 11.2 & 16.5 & 13.4 & 13.2 & 9.4 & 10.5 & 14 \\
\hline Chr & 24.7 & 17.7 & & & 19.7 & 15.7 & 21.8 & & 14 & 11.2 \\
\hline $\mathrm{BbF}$ & 8.2 & 5.4 & 5.9 & 4.52 & 10.6 & 9.4 & 8.6 & 4.8 & & $11.2^{j}$ \\
\hline $\mathrm{BkF}$ & 7.0 & 5.0 & 2.2 & 1.74 & 1.9 & 1.5 & 1.5 & 1.4 & & \\
\hline $\mathrm{BeP}$ & 13.9 & 8.6 & & & 3.2 & 2.9 & 4 & 6 & 4 & 6.4 \\
\hline $\mathrm{BaP}$ & 18.6 & 13.4 & 8.8 & 6.21 & 11 & 10.3 & 7.9 & & 4.6 & 7.6 \\
\hline Pyl & 2.1 & 1.7 & & & & & & & 0.9 & 3.5 \\
\hline IcdP & 8.2 & 5.2 & 5.9 & 2.55 & & & 3.5 & 2.5 & & \\
\hline DahA & 1.1 & 0.8 & 4.7 & $<0.97$ & & & 0.6 & 0.7 & 0.4 & 2.3 \\
\hline BghiP & 2.1 & 1.4 & & & & & 2.5 & & 1 & 2.3 \\
\hline $\mathrm{TPM}^{k}\left(\mathrm{mg} \mathrm{cig}^{-1}\right)$ & 13.8 & 9.4 & & 9.3 & & & 11 & 10.3 & 10.9 & \\
\hline
\end{tabular}

${ }^{a}$ This study. ${ }^{b} \operatorname{Ref} 16 .{ }^{c} \operatorname{Ref} 26 .{ }^{d} \operatorname{Ref} 1 .{ }^{e} \operatorname{Ref} 27 .{ }^{f} \operatorname{Ref} 5 .{ }^{g} \operatorname{Ref} 28 .{ }^{h} \operatorname{Ref} 29 .{ }^{i}$ Compounds are given abbreviations as follows: naphthalene (Nap), acenaphthylene (Acey), acenaphthene (Ace), fluorene ( $\mathrm{Fl}$ ), phenanthrene (Phe), anthracene (Ant), fluoranthene (Flu), pyrene (Pyr), benz $[\mathrm{a}]$ anthracene $(\mathrm{BaA})$, chrysene $(\mathrm{Chr})$, benzo[b]fluoranthene $(\mathrm{BbF})$, benzo[k]fluoranthene $(\mathrm{BkF})$, benzo[e]pyrene $(\mathrm{BeP})$, benzo[a]pyrene $(\mathrm{BaP})$, Perylene (Pyl), indeno[1,2,3-cd]pyrene (IcdP), dibenz[a,h]anthracene (DahA), and benzo[g,h,i]perylene $(\mathrm{BghiP}) .{ }^{j} \mathrm{BbF}+\mathrm{BkF} .{ }^{{ }^{k}} \mathrm{Total}$ particulate matter.

determined by previous studies, ${ }^{1,16,26}$ the TPM level was only reported by Roemer et al., ${ }^{26}$ and it was almost the same as that measured in our study (Table 1), although the PAHs emitted per cigarette in our study were much higher. Compared to the amounts of PAHs emitted per cigarette by Ding et al., ${ }^{1}$ our results were lower for most $\mathrm{PAHs}$ except for $\mathrm{BaA}, \mathrm{BkF}, \mathrm{BeP}$, and $\mathrm{BaP}$. However, levels of $\mathrm{BbF}$ and IcdP quite approximated that reported by Ding et al. ${ }^{16}$ The differences in measured PAH levels for 2R4F between studies might be partly caused by the numbers of cigarettes being smoked; only 1-3 cigarettes were smoked by Ding et al., ${ }^{1,16}$ whereas 20 or 30 cigarettes were smoked by Roemer et al. ${ }^{26}$ and 20 cigarettes were smoked in this study. Different pretreatment and instrumental determination procedures could also be reasons for the different levels measured for the same species. As shown in Table 1, none of previous studies reported all the listed $18 \mathrm{PAH}$ species for 2R4F or $1 \mathrm{R} 4 \mathrm{~F}$ as we did. Comparison of our 2R4F results with those reported for 1R4F also revealed similar TPM levels, while the individual PAHs fell into three categories; the levels of $\mathrm{NaP}$, Acey, Ace, and $\mathrm{Fl}$ were lower in 2R4F than in 1R4F; the levels of $\mathrm{BaA}, \mathrm{BkF}, \mathrm{BeP}, \mathrm{BaP}$; and IcdP in $2 \mathrm{R} 4 \mathrm{~F}$ were higher in $2 \mathrm{R} 4 \mathrm{~F}$ than in 1R4F; and the levels of remaining PAHs in 2R4F fell into the range of literature data for $1 \mathrm{R} 4 \mathrm{~F}$ (Table 1).

PAH Levels in Different Commercial Cigarettes. Levels of individual PAHs in the MS of 13 commercial cigarettes are listed in Table S2 of the Supporting Information in comparison with previous particle-phase data for various cigarettes smoked using FTC/ISO conditions. ${ }^{1,4-7,9-11,16,27,28}$ The ranges for 6 parent PAHs, namely, $\mathrm{BaA}, \mathrm{BbF}, \mathrm{BkF}, \mathrm{BaP}, \mathrm{DahA}$, and IcdP, were wider than those reported in the IARC monograph, ${ }^{30}$ in which the data were obtained more than 30 years ago.

Emission of individual PAH compounds varied from 0.1 to $1123.1 \mathrm{ng} \mathrm{cig}^{-1}$ and also exhibited large variations across different brands, despite that they fell into the broad range of literature data, which covered 1-3 orders of magnitude (Table S2, Supporting Information). The average RSD for individual species ranged from $21 \%$ for dibenzothiophene (DBT) to $182 \%$ for benzo[c]phenanthrene, with an average of 52\%. The variations in the compositions of PAHs could be associated with many factors including tobacco types and blends; ingredient types; filter types, size and ventilation; manufacturing processes; and even analytical procedures. ${ }^{1}$ Notably, PAHs generated from Kent were 1 order of magnitude less than those from others probably due to higher ventilation.

The average TPM yield for the cigarettes tested was $15.7 \pm$ $4.7 \mathrm{mg} \mathrm{cig}^{-1}$, with a less variation (RSD 30\%) compared to PAHs. These TPM levels were similar to that of $15.5 \pm 3.0 \mathrm{mg}$ $\mathrm{cig}^{-1}$ reported by Akpan et al. ${ }^{4}$ for 20 brands of Chinese cigarettes and close to those for some custom-made blended cigarettes $\left(8.61-11.01 \mathrm{mg} \mathrm{cig}^{-1}\right)^{10}$ and blended United States market cigarettes $\left(2-28.6 \mathrm{mg} \mathrm{cig}^{-1}\right),{ }^{5}$ but much lower than the mean value determined by Moir et al. $\left(46.9 \mathrm{mg} \mathrm{cig}^{-1}\right){ }^{7} \mathrm{~A}$ Pearson correlation analysis indicated most PAHs were strongly correlated with each other $(r=0.514-0.996, p<0.05)$ and with TPM $(r=0.522-0.862, p<0.05)$. The average RSD of PAHs/TPM was slightly lowered (RSD 47\%) compared to that of PAHs.

Table 2 presents a summary of total and grouped PAHs from this study. Total concentrations of PAHs ranged from $244.2 \pm$ $28.5 \mathrm{ng} \mathrm{cig}^{-1}$ in Kent to $10254.8 \pm 481.5 \mathrm{ng} \mathrm{cig}^{-1}$ in YZB. Among the three groups of PAHs, alkylated PAHs were the most abundant and comprised of $64-74 \%$ of the total PAH concentrations, followed by parent PAHs (16-23\%) and S/O PAHs (6-18\%). If we further divided the parent PAHs into three groups based on their molecular weights (MW) as low MW parent PAHs (LP-PAHs, MW 128-178 amu), medium MW parent PAHs (MP-PAHs, MW 202-228 amu), and high MW parent PAHs (HP-PAHs, MW 252-302 amu), LP-PAHs 
dominated the total parent PAHs, with shares ranging from $46 \%$ to $74 \%$, followed by MP-PAHs (18-40\%) and HP-PAHs (7-14\%). This dominance of LP-PAHs over MP- and HPPAHs in MS of cigarettes was also observed in many previous studies. ${ }^{1,6,7,11}$ At low to moderate combustion temperature, alkylated and LP-PAHs are abundant, ${ }^{24}$ consistent with the feature of cigarette smoking. ${ }^{5}$

The U.S. Enivironmental Protection Agency (USEPA) has identified 16 priority PAHs on the basis of evidence that they cause or may cause cancer. Total 16 priority $\mathrm{PAH}$ concentrations $\left(\sum_{16} \mathrm{PAHs}\right)$ in the 13 commercial cigarettes ranged 34.3-1775.7 $\mathrm{ng} \mathrm{cig}^{-1}$ (Table 2), close to that in other cigarettes reported by Hearn et al. (241.7-471.8 $\mathrm{ng} \mathrm{cig}{ }^{-1}$, without IcdP, DahA and BghiP), ${ }^{11}$ Ding et al. (86.2-2690.7 ng $\mathrm{cig}^{-1}$, without IcdP, DahA and BghiP), ${ }^{1}$ Ding et al. (797.6$2664.8 \mathrm{ng} \mathrm{cig}^{-1}$, without IcdP, DahA and BghiP), ${ }^{6}$ and Rustemeier et al. (630.8-912.4 ng cig ${ }^{-1}$, without $\mathrm{BbF}$ and $\mathrm{BkF}),{ }^{10}$ but lower than that measured in a commercial brand by Moir et al. (4910.7 $\left.\mathrm{ng} \mathrm{cig}^{-1}\right){ }^{7}$ Nevertheless, less discrepancy between this study and the literatures would occur when $\sum_{16}$ PAHs was normalized by TPM; the range of $\sum_{16} \mathrm{PAHs} /$ TPM was $4.8-93.1 \mathrm{ng} \mathrm{mg}^{-1}$ in our study and $57.3-104.7 \mathrm{ng}$ $\mathrm{mg}^{-1}$ in previous ones.

Carcinogenic Potency. BaP has been used as an indicator of total PAHs and their carcinogenicity. ${ }^{31}$ It is also the most frequently reported $\mathrm{PAH}$ in the literature on cigarette smoke studies. ${ }^{1} \mathrm{BaP}$ levels for most cigarette brands measured in this study were within the literature range (1.3-36.3, Table S2, Supporting Information), whereas relatively lower yield for Kent (1.1 $\left.\mathrm{ng} \mathrm{cig}^{-1}\right)$ and higher yields for JZ (41.6 $\left.\mathrm{ng} \mathrm{cig}^{-1}\right)$, LQ $\left(37.4 \mathrm{ng} \mathrm{cig}^{-1}\right)$, and YZB (40.3 ng cig $\left.{ }^{-1}\right)$ were observed. As $\mathrm{BaP}$ is only one of many carcinogenic PAHs in tobacco smoke, a more reasonable assessment of the carcinogenicity could be achieved by including more carcinogenic PAH species. As a consequence, the $\mathrm{BaP}$ equivalent concentration $\left(\mathrm{BaP}_{\text {eq }}\right)$ is typically calculated by using $\mathrm{BaP}$ as a reference congener and summing up the potencies of individual carcinogenic PAHs with their relative potency factors (RPFs, Table S2) obtained from USEPA. ${ }^{32}$ The carcinogenic potencies of individual PAHs and their contributions to the $\mathrm{BaP}_{\text {eq }}$ in the present study are listed in Table 3 in comparison with those in several Chinese, ${ }^{4}$ United States, $^{5,16}$ Canadian, $^{7}$ and European cigarette brands. ${ }^{33}$

The $\mathrm{BaP}_{\mathrm{eq}}$ values for the 13 commercial cigarettes ranged from 3.6 to $120.2 \mathrm{ng} \mathrm{cig}^{-1}$, with an average of $71.7 \mathrm{ng} \mathrm{cig}^{-1}$, comparable to the calculated values from Akpan et al., ${ }^{4}$ Roemer et al., ${ }^{5}$ Moir et al., ${ }^{7}$ Ding et al., ${ }^{16}$ and Lodovici et al. ${ }^{33} \mathrm{BaP}_{\mathrm{eq}}$ levels seemed to be higher in flue-cured cigarettes (70.0-120.2 $\left.\mathrm{ng} \mathrm{cig}^{-1}\right)$ than in blended ones $\left(3.6-52.5 \mathrm{ng} \mathrm{cig}^{-1}\right)$, except for similar levels in BS $\left(60.8 \pm 0.1 \mathrm{ng} \mathrm{cig}^{-1}\right)$ and WBL $(66.1 \pm 23.4$ ng $\left.\mathrm{cig}^{-1}\right)$. BaP and DahA were found to be the two largest contributors to $\mathrm{BaP}_{\text {eq }}$ with shares of $29.2-45.2 \%$ and $9.7-$ $40.0 \%$, respectively, similar to the results from Roemer et al. $(29.2-30.8 \% \text { and } 38.1-41.2 \%)^{5}$ and Moir et al. $(27.2 \%$ and $21.9 \%)^{7}$ (Table 3). However, DahA was the dominant contributor to $\mathrm{BaP}_{\text {eq }}$ in the 20 Chinese brands measured by Akpan et al. (68.1-85.7\%), ${ }^{4} 9$ United States brands reported by Ding et al. (52.9-66.0\%), ${ }^{16}$ and 14 European brands measured by Lodovici et al. $\left(40.8-81.1 \%\right.$, gas+particle phase). ${ }^{33}$ It was noteworthy that the carcinogenic potency of the cigarette smoke was likely to be underestimated in this study because only a handful of PAHs were taken into account and to a lesser extent, only particle-phase concentrations were measured. For example, dibenzo[a,1]pyrene has a high RPF value of $30 .{ }^{32}$ 
Table 3. Carcinogenic Potency of Individual PAHs and Their Contributions, ng cig $^{-1}$ (\%), to the $\mathrm{BaP}_{\mathrm{eq}}$

\begin{tabular}{|c|c|c|c|c|c|c|}
\hline & this study & 20 Chinese brands $^{a}$ & 8 United States brands ${ }^{b}$ & 9 United States brands ${ }^{c}$ & $\begin{array}{l}\text { 1 Canadian } \\
\text { brand }^{d}\end{array}$ & 14 European brands ${ }^{e}$ \\
\hline Flu & $5.6-126.5(5.7-12.6)$ & & & & $7.7(14.7)$ & $1.0-5.6(2.8-19.8)$ \\
\hline $\mathrm{CPcdP}^{f}$ & $0.5-12.1(0.6-5.7)$ & & & & & \\
\hline $\mathrm{BaA}$ & $2.0-56.4(6.6-11.1)$ & $1.5-5.1(1.5-5.6)$ & $2.4-5.4(10.3-11.1)$ & $7.6-13.3(10.0-16.0)$ & $6.1(11.6)$ & $0.8-1.8(1.8-7.3)$ \\
\hline $\mathrm{Chr}$ & $2.5-64.4(3.5-6.9)$ & $2.0-7.2(1.8-8.3)$ & & & $3.9(7.4)$ & $0.7-8.0(2.8-18.6)$ \\
\hline $\mathrm{BbF}$ & $0.5-17.7(9.2-16.6)$ & $1.4-11.6(1.2-11.6)$ & $4.6-9.1(17.5-19.6)$ & $4.1-9.7(7.0-12.5)$ & $8.6(16.4)$ & $0.8-5.2(1.8-11.3)$ \\
\hline $\mathrm{BkF}$ & $0.6-17.1(0.3-0.5)$ & $0.0-0.2(0.0-0.1)$ & $0.1-0.1(0.2-0.3)$ & $0.1-0.2(0.1-0.2)$ & $0.1(0.2)$ & $0.0-0.0(0.0-0.1)$ \\
\hline $\mathrm{BaP}$ & $1.1-41.6(29.2-45.2)$ & $5.8-14.2(5.1-12.4)$ & $7.2-14.5(29.2-30.8)$ & $10.0-15.8(13.8-19.0)$ & $14.3(27.2)$ & $1.9-5.1(5.6-17.7)$ \\
\hline $\operatorname{IcdP}$ & $0.3-18.1(0.5-1.5)$ & & $0.2-0.5(0.8-1.0)$ & $0.5-0.8(0.6-1.0)$ & $0.3(0.6)$ & \\
\hline DahA & $0.1-3.3(9.7-40.0)$ & $32.0-189.0(68.1-85.7)$ & $8.9-18.7(38.1-41.2)$ & $36.0-62.0(52.9-66.0)$ & $11.5(21.9)$ & $9.0-72.0(40.8-81.1)$ \\
\hline BghiP & $0.1-6.9(0.0-0.1)$ & & & & $0.0(0.1)$ & $0.0-0.0(0.0-0.1)$ \\
\hline Sum & $3.6-120.2(100)$ & $46.6-222.7(100)$ & $23.3-48.3(100)$ & $58.6-100.3(100)$ & $52.6(100)$ & $19.8-88.8(100)$ \\
\hline
\end{tabular}

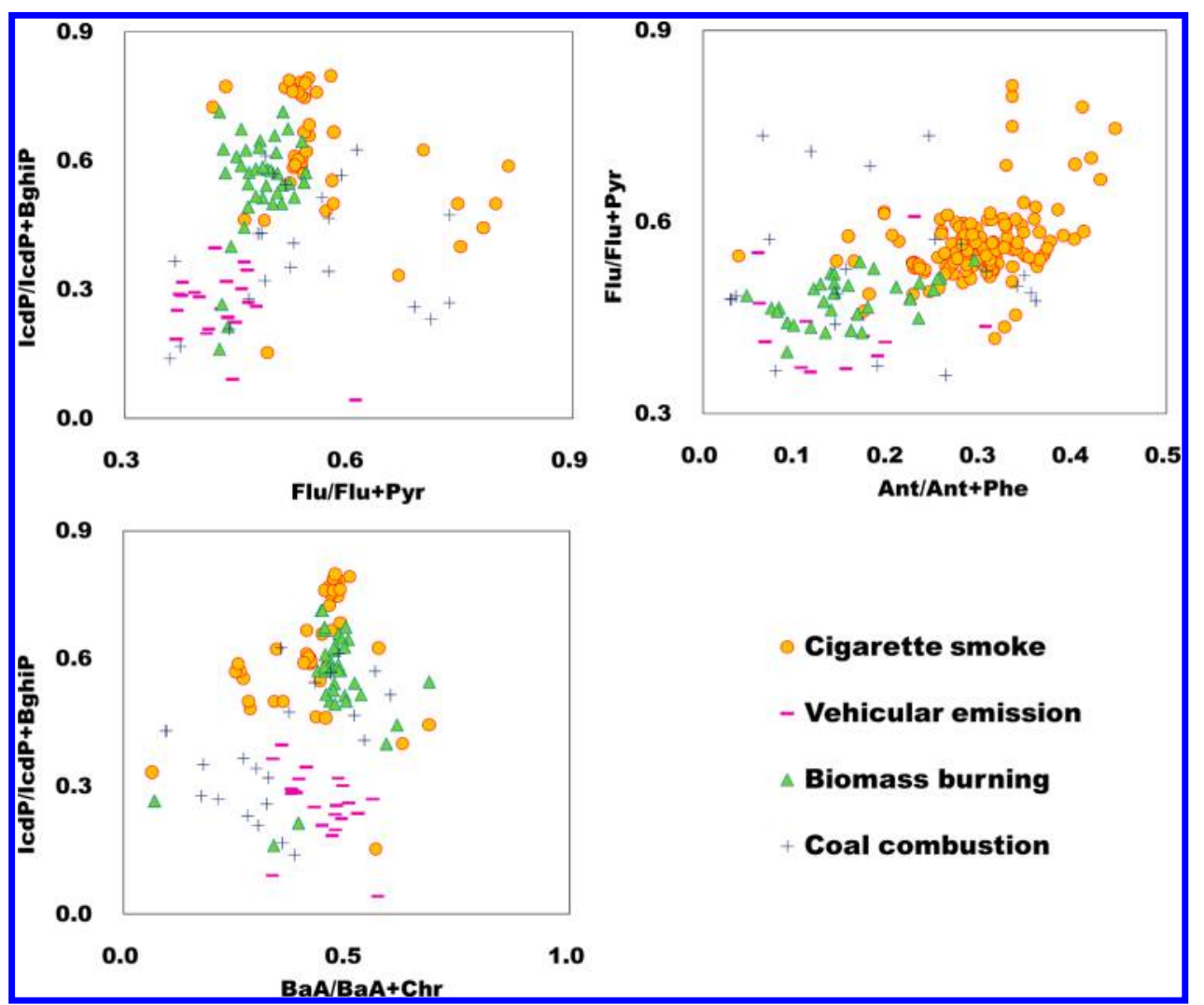

Figure 1. Cross plots for parent PAH ratios in cigarette smoke, vehicular emission, biomass burning, and coal combustion. Both values measured in this study and reported in the literature were used for cigarette smoke.

However, dibenzopyrenes were not included in the estimation of $\mathrm{BaP}_{\mathrm{eq}}$ because the four isomers, dibenzo[a.e]pyrene, dibenzo[a,h]pyrene, dibenzo[a,i]pyrene, and dibenzo[a,l]pyrene were difficult to be cleanly separated by the GC column we used.

Discrimination of Cigarette Smoke from Other Sources Using Diagnostic Ratios. Parent PAHs. Ratios of several parent PAHs, such as Ant/(Ant+Phe), Flu/(Flu+Pyr), $\mathrm{BaA} /(\mathrm{BaA}+\mathrm{Chr}), \mathrm{IcdP} /(\mathrm{IcdP}+\mathrm{BghiP})$, and $\mathrm{BaP} / \mathrm{BghiP}$, have been widely used as diagnostic tools to trace possible emission sources. ${ }^{19,20}$ As vehicular exhausts (VE), biomass burning (BB), and coal combustion (CC) are documented as the three most common sources of PAHs, ${ }^{34-36}$ we compared these ratios derived from $\mathrm{PAHs}$ measured in particle-phase for cigarette smoke (including MS, sidestream smoke and ETS) with those for $\mathrm{VE}, \mathrm{BB}$, and $\mathrm{CC}$ (Table S3) to examine whether cigarette smoke can be distinguished from other sources. Apparently, none of these ratios can differentiate the sources due to large variation for each source type and overlaps between different sources.

Figure 1 further compares the diagnostic ratios of typical $\mathrm{PAH}$ isomer pairs using cross plots. The dots of cigarette smoke exhibited remarkable overlap with those of $\mathrm{BB}$ and $\mathrm{CC}$ but were largely separate from that of $\mathrm{VE}$, indicating the cross plots of $\mathrm{PAH}$ isomer pairs could possibly distinguish cigarette smoke from VE. However, caution is required for ambient data because the ratios may undergo change during transport due to differential partitioning, degradation and scavenging. ${ }^{34}$ In addition, it is recognized that not all smokers smoke their cigarettes in the same way. Potential differences in smoking behavior, such as puff volume and frequency and blockage of cigarette ventilation holes, may give rise to changes in the 

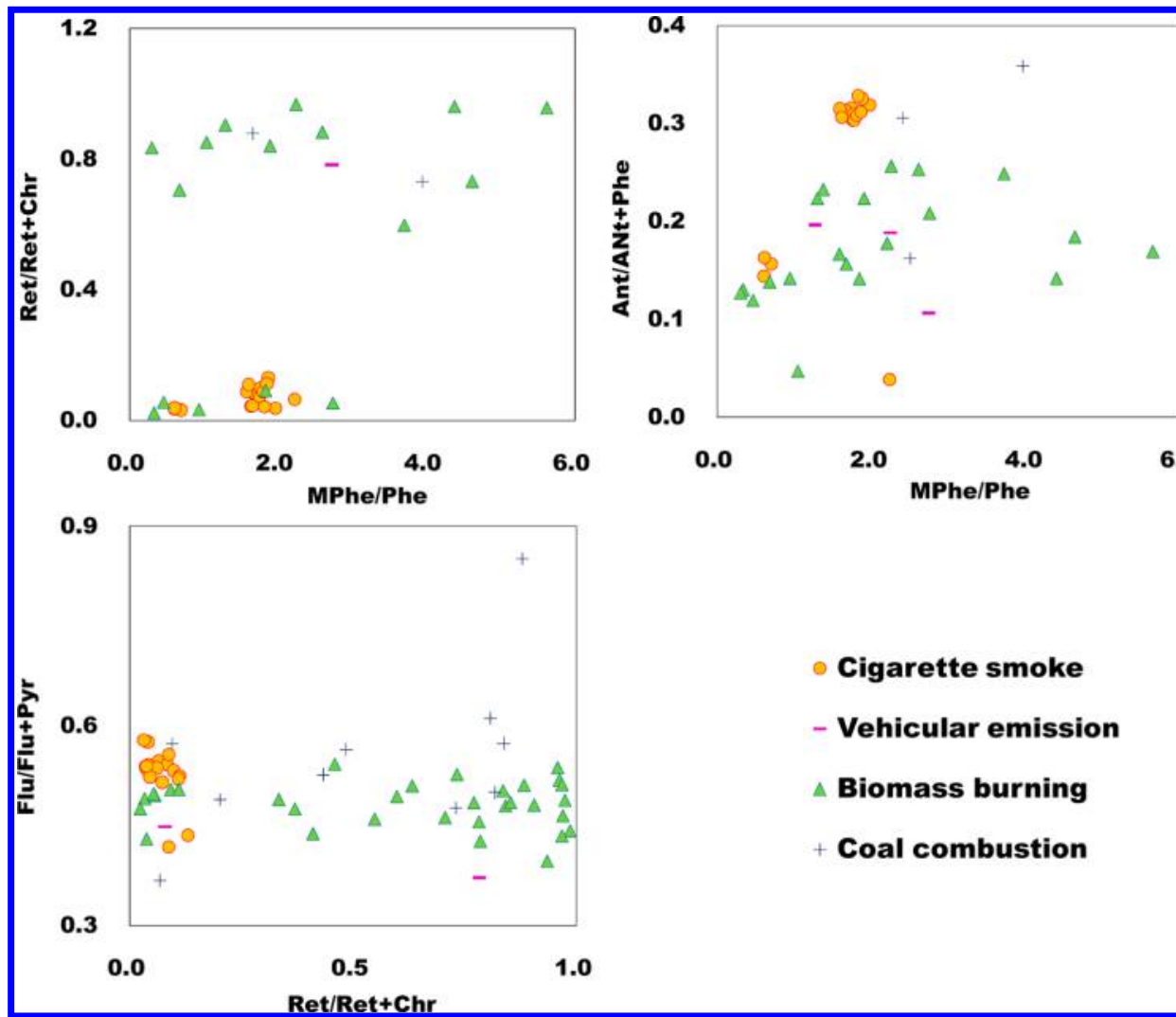

- Cigarette smoke

- Vehicular emission

Biomass burning

Coal combustion

Figure 2. Cross plots for alkylated PAH ratios in cigarette smoke, vehicular emission, biomass burning, and coal combustion. Both values measured in this study and reported in the literature were used for cigarette smoke.

relative yields of tobacco combustion products. ${ }^{5,7,16}$ These factors will likely result in similar ratios for cigarette smoke and other sources.

Alkylated and S/O PAHs. Due to high structural variability, alkylated PAHs possess the potential to improve source discrimination. Relative concentrations of parent versus alkylated PAHs have been proposed to discriminate combustion from petrogenic emissions, with combustion characterized by a low proportion of alkyl-PAHs. ${ }^{37}$ However, comparison of $\sum$ parent versus $\sum$ alkylated between this study and literature data is hindered by the fact that previous source profiles do not contain or only contain a few alkylated PAHs and their isomers. Measurements of all the parent, alkylated, and S/O PAHs are rarer. In a recent research, Schuster et al. suggested that the ratios $\sum$ parent/ $\sum$ alkylated $\sim 0.2$ and $\sum$ parent/DBTs $\sim 5$ were generally representative of the Athabasca oil sands mining region, ${ }^{38}$ and the ratios in another industrial region, Hamilton Harbour, Ontario, were 0.38 and 0.94 , respectively. In this study, these ratios averaged 1.05 and 0.41 , respectively, but the species and number of PAHs for calculating $\sum$ parent, $\sum$ alkylated, and DBTs had minor differences with those in Schuster et al. ${ }^{38}$

Retene (Ret) has been used as a typical tracer for either wood combustion ${ }^{39}$ or for degradation products of conifer resins. ${ }^{40}$ DBT also acts as an indicator of combustion of sulfurcontaining fuels such as coal and diesel. ${ }^{39}$ However, both were detected in our MS sample and Ret was also detected in ETS, ${ }^{41}$ $\mathrm{VE}^{42-44}$ and $\mathrm{CC}^{45,46}$ Therefore, ratios containing these compounds rather than the absolute concentrations may be more suitable to distinguish sources. Ret/(Ret+Chr), Phe/(Phe $+\mathrm{DBT})$, and $\mathrm{DBT} /(\mathrm{DBT}+\mathrm{Ret})$ have been used to characterize the sources in environmental samples. ${ }^{22,37,47}$ Methylphenan- threnes/phe (MPhe/Phe, MPhe includes 1-, 2-, 3-, and 9$\mathrm{MPhe}$ ) is also a frequently used indicator to differentiate between petrogenic and pyrogenic sources. ${ }^{24,48}$ Table S4 of the Supporting Information lists the ratios for different sources. Similar to parent PAHs, single ratios cannot satisfactorily distinguish cigarette smoke from other sources. Only a few ratios with $\mathrm{S} / \mathrm{O}$-containing PAHs were reported, such as Phe/ (Phe+DBT) $\sim 1.0$ and DBT/(DBT+Ret) $\sim 0.6$ by Wingfors et al. ${ }^{42}$ for VE and Phe/(Phe+DBT) $\sim 0.6$ by Grimmer et al. ${ }^{49}$ for CC. Unfortunately, these ratios fell into ranges for MS measured in this study. However, with the cross plots (Figure 2) involving more alkylated PAHs, the discrimination of cigarette smoke from CC seemed to be improved by the Ret/ (Ret+Chr)-MPhe/Phe plot based on limited MPhe and Ret data in published source profiles. ${ }^{44,46,50-54}$ Anyway, future research is required when more source profiles containing alkylated and S/O PAHs are available.

Implications and Limitations. In this study, we obtained a much wider spectrum of PAHs in mainstream cigarette smoke for popular cigarette brands sold in China's markets. The doses of $\mathrm{BaP}$ and $\mathrm{BaP}_{\mathrm{eq}}$ by smoking one cigarette of these brands averaged 26.6 and $75.9 \mathrm{ng}$, respectively; they were comparable or even higher than the daily doses for adults through inhalation exposure ( 31.2 and $42.3 \mathrm{ng}$, respectively), based on Nouwen equation, ${ }^{55}$ in which the concentrations of particulate PAHs were taken from measured ambient values in urban Guangzhou on a day with highly polluted air. ${ }^{56}$ Although we calculated $\mathrm{BaP}_{\mathrm{eq}}$ to indicate carcinogenic potency, it must be stressed this simplified calculation only takes limited parent PAH species into consideration, and there are numerous alkylated and heteroatmoic PAHs in cigarette smoke with health effects still unknown. The extended chemical speciation 
of PAHs in cigarette smoke would not only help us understand air toxics released by smoking but also improve source attribution of PAHs. While cross plots of parent PAH pairs could only possibly distinguish cigarette smoke from vehicle exhausts, discrimination between cigarette smoke and coal combustion is enhanced with more alkylated PAHs involved. However, as cigarette smoke is in its nature a kind of biomass burning, it remains difficult to distinguish cigarettes smoke from other biomass burning sources. Compared to parent and alkylated PAHs, S/O PAHs and other heteroatomic PAHs were much less reported in published source profiles. To measure more heteroatomic PAHs in source profiles in future would benefit to exploring more fingerprints for better source attribution of PAHs occurring in indoor and outdoor environments. It is worth noting that this source attribution would be further complicated by atmospheric processes such as gas-particle partitioning and air mass aging.

\section{ASSOCIATED CONTENT}

\section{S Supporting Information}

Tables outlining the characteristics of cigarettes smoked, yields of individual $\mathrm{PAH}$ and diagnostic ratios of parent, alkylated and $\mathrm{S} / \mathrm{O} \mathrm{PAHs}$ in cigarette smoke, and other sources. The Supporting Information is available free of charge on the ACS Publications website at DOI: 10.1021/acs.est.5b01108.

\section{AUTHOR INFORMATION}

\section{Corresponding Author}

*Tel: +86-20-85290180. Fax: +86-20-85290706. E-mail: wangxm@gig.ac.cn.

Notes

The authors declare no competing financial interest.

\section{ACKNOWLEDGMENTS}

This study was funded by the Natural Science Foundation of China (Project No. 41025012/41121063/41403093), Strategic Priority Research Program of the Chinese Academy of Sciences (Grant No. XDB05010200), the Bureau of Science, Technology and Information of Guangzhou (Project No. 201300000130), and EU FP7 project (AMIS, No. 069720).

\section{REFERENCES}

(1) Ding, Y. S.; Trommel, J. S.; Yan, X. Z. J.; Ashley, D.; Watson, C. $\mathrm{H}$. Determination of 14 polycyclic aromatic hydrocarbons in mainstream smoke from domestic cigarettes. Environ. Sci. Technol. 2005, 39 (2), 471-478.

(2) Lu, H.; Zhu, L. Z. Pollution patterns of polycyclic aromatic hydrocarbons in tobacco smoke. I. Hazard. Mater. 2007, 139 (2), 193-198.

(3) Mitra, S.; Ray, B. Patterns and sources of polycyclic aromatic hydrocarbons and their derivatives in indoor air. Atmos. Environ. 1995, 29 (22), 3345-3356.

(4) Akpan, V.; Huang, S.; Lodovici, M.; Dolara, P. High levels of carcinogenic polycyclic aromatic hydrocarbons (PAH) in 20 brands of Chinese cigarettes. I. Appl. Toxicol. 2006, 26 (6), 480-483.

(5) Roemer, E.; Stabbert, R.; Rustemeier, K.; Veltel, D. J.; Meisgen, T.; Reininghaus, W.; Carchman, R. A.; Gaworski, C. L.; Podraza, K. F. Chemical composition, cytotoxicity and mutagenicity of smoke from US commercial and reference cigarettes smoked under two sets of machine smoking conditions. Toxicology 2004, 195 (1), 31-52.

(6) Ding, Y. S.; Yan, X. Z. J.; Jain, R. B.; Lopp, E.; Tavakoli, A.; Polzin, G. M.; Stanfill, S. B.; Ashley, D. L.; Watson, C. H. Determination of 14 polycyclic aromatic hydrocarbons in mainstream smoke from US brand and non-US brand cigarettes. Environ. Sci. Technol. 2006, 40 (4), 1133-1138.

(7) Moir, D.; Rickert, W. S.; Levasseur, G.; Larose, Y.; Maertens, R.; White, P.; Desjardins, S. A comparison of mainstream and sidestream marijuana and tobacco cigarette smoke produced under two machine smoking conditions. Chem. Res. Toxicol. 2008, 21 (2), 494-502.

(8) Hecht, S. S. Tobacco smoke carcinogens and lung cancer. $\underline{\text {. Natl. }}$ Cancer Inst. 1999, 91 (14), 1194-1210.

(9) Tarrant, J. E.; Mills, K.; Williard, C. Development of an improved method for the determination of polycyclic aromatic hydrocarbons in mainstream tobacco smoke. L. Chromatogr. A 2009, 1216 (12), 22272234.

(10) Rustemeier, K.; Stabbert, R.; Haussmann, H. J.; Roemer, E.; Carmines, E. L. Evaluation of the potential effects of ingredients added to cigarettes. Part 2: Chemical composition of mainstream smoke. Food Chem. Toxicol. 2002, 40 (1), 93-104.

(11) Hearn, B. A.; Ding, Y. S.; Vaughan, C.; Zhang, L.; Polzin, G.; Caudill, S. P.; Watson, C. H.; Ashley, D. L. Semi-volatiles in mainstream smoke delivery from select charcoal-filtered cigarette brand variants. Tob. Control 2010, 19 (3), 223-230.

(12) Severson, R. F.; Snook, M. E.; Arrendale, R. F.; Chortyk, O. T. Gas-Chromatographic Quantitation of Polynuclear Aromatic-Hydrocarbons in Tobacco-Smoke. Anal. Chem. 1976, 48 (13), 1866-1872.

(13) Snook, M. E.; Severson, R. F.; Arrendale, R. F.; Higman, H. C.; Chortyk, O. T. Multi-Alkylated Polynuclear Aromatic-Hydrocarbons of Tobacco-Smoke - Separation and Identification. Beitr. Tabakforsch. Int. 1978, 9 (4), 222-247.

(14) Swartz, C. D.; King, L. C.; Nesnow, S.; Umbach, D. M.; Kumar, S.; DeMarini, D. M. Mutagenicity, stable DNA adducts, and abasic sites induced in Salmonella by phenanthro[3,4-b]- and phenanthro[4,3-b]thiophenes, sulfur analogs of benzo[c]phenanthrene. Mutat. Res., Fundam. Mol. Mech. Mutagen. 2009, 661 (1-2), 47-56.

(15) Sun, Y.; Miller, C. A., III; Wiese, T. E.; Blake, D. A. Methylated phenanthrenes are more potent than phenanthrene in a bioassay of human aryl hydrocarbon receptor (AhR) signaling. Environ. Toxicol. Chem. 2014, 33 (10), 2363-2367.

(16) Ding, Y. S.; Ashley, D. L.; Watson, C. H. Determination of 10 carcinogenic polycyclic aromatic hydrocarbons in mainstream cigarette smoke. I. Agric. Food Chem. 2007, 55 (15), 5966-5973.

(17) Huang, S. H.; Ge, X. M.; Tang, J. H.; Akpan, V.; Lodovlci, M.; Dolara, P. Content of polycyclic aromatic hydrocarbon (PAHs) in mainstream smoke of Chinese cigarettes. J. Environ. Health. (Chinese) 2006, 23 (1), 46-48.

(18) Du, X. Q.; Wang, X. M.; Tang, J. H.; Ding, X.; Lin, H. T.; Li, Z.; Sheng, G. Y.; Fu, J. M. Polycyclic aromatic hydrocarbons in mainstream smoke from major cigarette brands sold in China. Environ. Chem. (Chinese) 2006, 25 (6), 785-788.

(19) Ding, X.; Wang, X. M.; Xie, Z. Q.; Xiang, C. H.; Mai, B. X.; Sun, L. G.; Zheng, M.; Sheng, G. Y.; Fu, J. M.; Poschl, U. Atmospheric polycyclic aromatic hydrocarbons observed over the North Pacific Ocean and the Arctic area: Spatial distribution and source identification. Atmos. Environ. 2007, 41 (10), 2061-2072.

(20) Yunker, M. B.; Macdonald, R. W.; Vingarzan, R.; Mitchell, R H.; Goyette, D.; Sylvestre, S. PAHs in the Fraser River basin: a critical appraisal of $\mathrm{PAH}$ ratios as indicators of $\mathrm{PAH}$ source and composition. Org. Geochem. 2002, 33 (4), 489-515.

(21) Sofowote, U. M.; McCarry, B. E.; Marvin, C. H. Source apportionment of $\mathrm{PAH}$ in Hamilton Harbour suspended sediments: Comparison of two factor analysis methods. Environ. Sci. Technol. 2008, 42 (16), 6007-6014.

(22) Lehndorff, E.; Schwark, L. Biomonitoring airborne parent and alkylated three-ring PAHs in the Greater Cologne Conurbation I: Temporal accumulation patterns. Environ. Pollut. 2009, 157 (4), $1323-1331$

(23) Mai, B. X.; Fu, H. M.; Sheng, G. Y.; Kang, Y. H.; Lin, Z.; Zhang, G.; Min, Y. S.; Zeng, E. Y. Chlorinated and polycyclic aromatic hydrocarbons in riverine and estuarine sediments from Pearl River Delta, China. Environ. Pollut. 2002, 117 (3), 457-474. 
(24) Mai, B. X.; Qi, S. H.; Zeng, E. Y.; Yang, Q. S.; Zhang, G.; Fu, J. M.; Sheng, G. Y.; Peng, P. N.; Wang, Z. S. Distribution of polycyclic aromatic hydrocarbons in the coastal region off Macao, China: Assessment of input sources and transport pathways using compositional analysis. Environ. Sci. Technol. 2003, 37 (21), 4855-4863.

(25) Chen, P. X.; Moldoveanu, S. C. Mainstream smoke chemical analyses for $2 \mathrm{R} 4 \mathrm{~F}$ Kentucky reference cigarette. Beitr. Tabakforsch. Int. 2003, 20 (7), 448-458.

(26) Roemer, E.; Schramke, H.; Weiler, H.; Buettner, A.; Kausche, S.; Weber, S.; Berges, A.; Stueber, M.; Muench, M.; Trelles-Sticken, E.; Pype, J.; Kohlgrueber, K.; Voelkel, H.; Wittke, S. Mainstream Smoke Chemistry and in Vitro and In Vivo Toxicity of the Reference Cigarettes 3R4F and 2R4F. Beitr. Tabakforsch./ Contrib. Tob. Res. 2012, 1 .

(27) Forehand, J. B.; Dooly, G. L.; Moldoveanu, S. C. Analysis of polycyclic aromatic hydrocarbons, phenols and aromatic amines in particulate phase cigarette smoke using simultaneous distillation and extraction as a sole sample clean-up step. I. Chromatogr. A 2000, 898 (1), 111-124.

(28) Zha, Q.; Qian, N. X.; Moldoveanu, S. C. Analysis of polycyclic aromatic hydrocarbons in the particulate phase of cigarette smoke using a gas chromatographic-high-resolution mass spectrometric technique. I. Chromatogr. Sci. 2002, 40 (7), 403-408.

(29) Gmeiner, G.; Stehlik, G.; Tausch, H. Determination of seventeen polycyclic aromatic hydrocarbons in tobacco smoke condensate. I. Chromatogr. A 1997, 767 (1-2), 163-169.

(30) Tobacco Smoke and Involuntary Smoking; IARC Monographs on the Evaluation of Carcinogenic Risks to Humans, 2004, Volume 83.

(31) Bostrom, C. E.; Gerde, P.; Hanberg, A.; Jernstrom, B.; Johansson, C.; Kyrklund, T.; Rannug, A.; Tornqvist, M.; Victorin, K.; Westerholm, R. Cancer risk assessment, indicators, and guidelines for polycyclic aromatic hydrocarbons in the ambient air. Environ. Health Perspect. 2002, 110, 451-488.

(32) Development of a Relative Potency Factor (RPF) Approach for Polycyclic Aromatic Hydrocarbon (PAH) Mixtures; External review draft; U.S. Environmental Protection Agency: Washington, DC, 2010; http://cfpub.epa.gov/ncea/iris_drafts /recordisplay.cfm?deid=194584 (accessed July 2015).

(33) Lodovici, M.; Akpan, V.; Evangelisti, C.; Dolara, P. Sidestream tobacco smoke as the main predictor of exposure to polycyclic aromatic hydrocarbons. I. Appl. Toxicol. 2004, 24 (4), 277-281.

(34) Sheesley, R. J.; Andersson, A.; Gustafsson, O. Source characterization of organic aerosols using Monte Carlo source apportionment of PAHs at two South Asian receptor sites. Atmos. Environ. 2011, 45 (23), 3874-3881.

(35) van Drooge, B. L.; Ballesta, P. P. Seasonal and Daily Source Apportionment of Polycyclic Aromatic Hydrocarbon Concentrations in PM10 in a Semirural European Area. Environ. Sci. Technol. 2009, 43 (19), 7310-7316.

(36) Gao, B.; Wang, X. M.; Zhao, X. Y.; Ding, X.; Fu, X. X.; Zhang, Y. L.; He, Q. F.; Zhang, Z.; Liu, T. Y.; Huang, Z. Z.; Chen, L. G.; Peng, Y.; Guo, H. Source apportionment of atmospheric PAHs and their toxicity using PMF: Impact of gas/particle partitioning. Atmos. Environ. 2015, 103 (0), 114-120.

(37) Lehndorff, E.; Schwark, L. Biomonitoring airborne parent and alkylated three-ring PAHs in the Greater Cologne Conurbation II: Regional distribution patterns. Environ. Pollut. 2009, 157 (5), 17061713.

(38) Schuster, J. K.; Harner, T.; Su, K.; Mihele, C.; Eng, A. First Results from the Oil Sands Passive Air Monitoring Network for Polycyclic Aromatic Compounds. Environ. Sci. Technol. 2015, 49 (5), 2991-2998.

(39) Ramdahl, T. Retene[mdash]a molecular marker of wood combustion in ambient air. Nature 1983, 306 (5943), 580-582.

(40) Simoneit, B. R. T.; Mazurek, M. A. Organic matter of the troposphere-II.* Natural background of biogenic lipid matter in aerosols over the rural western united states. Atmos. Environ. (19671989) 1982, 16 (9), 2139-2159.
(41) Bi, X. H.; Sheng, G. Y.; Feng, Y. L.; Fu, J. M.; Xie, J. X. Gas- and particulate-phase specific tracer and toxic organic compounds in environmental tobacco smoke. Chemosphere 2005, 61 (10), 15121522.

(42) Wingfors, H.; Sjodin, A.; Haglund, P.; Brorstrom-Lunden, E. Characterisation and determination of profiles of polycyclic aromatic hydrocarbons in a traffic tunnel in Gothenburg, Sweden. Atmos. Environ. 2001, 35 (36), 6361-6369.

(43) Emissions from Diesel and Gasoline Engines Measured in Highway Tunnels; Health Effects Institute: Boston, MA, 2002.

(44) He, L. Y.; Hu, M.; Huang, X. F.; Zhang, Y. H.; Yu, B. D.; Liu, D. $\mathrm{Q}$. Chemical characterization of fine particles from on-road vehicles in the Wutong tunnel in Shenzhen, China. Chemosphere 2006, 62 (10), $1565-1573$

(45) Zhang, Y. X.; Schauer, J. J.; Zhang, Y. H.; Zeng, L. M.; Wei, Y. J.; Liu, Y.; Shao, M. Characteristics of particulate carbon emissions from real-world Chinese coal combustion. Environ. Sci. Technol. 2008, 42 (14), 5068-5073.

(46) Oros, D. R.; Simoneit, B. R. T. Identification and emission rates of molecular tracers in coal smoke particulate matter. Fuel 2000, 79 (5), 515-536.

(47) Yan, B.; Abrajano, T. A.; Bopp, R. F.; Chaky, D. A.; Benedict, L. A.; Chillrud, S. N. Molecular Tracers of Saturated and Polycyclic Aromatic Hydrocarbon Inputs into Central Park Lake, New York City. Environ. Sci. Technol. 2005, 39 (18), 7012-7019.

(48) Lian, J. J.; Li, C. L.; Ren, Y.; Cheng, T. T.; Chen, J. M. Determination of Alkyl Polycyclic Aromatic Hydrocarbons in Dustfall by Supercritical Fluid Extraction Followed by Gas Chromatography/ Mass Spectrum. Bull. Environ. Contam. Toxicol. 2009, 82 (2), 189-193.

(49) Grimmer, G.; Jacob, J.; Dettbarn, G.; Naujack, K. W. Determination of Polycyclic Aromatic-Hydrocarbons, Azaarenes, and Thiaarenes Emitted from Coal-Fired Residential Furnaces by GasChromatography - Mass-Spectrometry. Fresenius' Z. Anal. Chem. 1985, 322 (6), 595-602.

(50) Schauer, J. J.; Kleeman, M. J.; Cass, G. R.; Simoneit, B. R. T. Measurement of emissions from air pollution sources. 3. C-1-C-29 organic compounds from fireplace combustion of wood. Environ. Sci. Technol. 2001, 35 (9), 1716-1728.

(51) Fine, P. M.; Cass, G. R.; Simoneit, B. R. T. Chemical characterization of fine particle emissions from fireplace combustion of woods grown in the northeastern United States. Environ. Sci. Technol. 2001, 35 (13), 2665-2675.

(52) Fine, P. M.; Cass, G. R.; Simoneit, B. R. T. Chemical characterization of fine particle emissions from the fireplace combustion of woods grown in the southern United States. Environ. Sci. Technol. 2002, 36 (7), 1442-1451.

(53) Fine, P. M.; Cass, G. R.; Simoneit, B. R. T. Chemical characterization of fine particle emissions from the wood stove combustion of prevalent United States tree species. Environ. Eng. Sci. 2004, 21 (6), 705-721.

(54) Hays, M. D.; Fine, P. M.; Geron, C. D.; Kleeman, M. J.; Gullett, B. K. Open burning of agricultural biomass: Physical and chemical properties of particle-phase emissions. Atmos. Environ. 2005, 39 (36), $6747-6764$

(55) Nouwen, J.; Cornelis, C.; De Fré, R.; Wevers, M.; Viaene, P.; Mensink, C.; Patyn, J.; Verschaeve, L.; Hooghe, R.; Maes, A.; Collier, M.; Schoeters, G.; Van Cleuvenbergen, R.; Geuzens, P. Health risk assessment of dioxin emissions from municipal waste incinerators: the Neerlandquarter (Wilrijk, Belgium). Chemosphere 2001, 43 (4-7), 909-923.

(56) Gao, B.; Yu, J. Z.; Li, S. X.; Ding, X.; He, Q. F.; Wang, X. M. Roadside and rooftop measurements of polycyclic aromatic hydrocarbons in PM2.5 in urban Guangzhou: Evaluation of vehicular and regional combustion source contributions. Atmos. Environ. 2011, 45 (39), 7184-7191. 